Phenacetine.-Contrary to some writers, phenacetine will give the isonitrile test, and hence cannot be distinguished from acetanilide by this reaction.'

Exalgine does not respond to this test because it is a secondary amine; hence a distinction from acetanilide, phenacetine, and phenocoll.

The odor of raspberries attributed to exalgine, when heated, is somewhat misleading. It is certainly aromatic, but may resemble either strawberries or mulberries.

By boiling acetanilide with an alkaline solution of sodium hypobromite $(\mathrm{NaBrO})$ or with alkaline permanganate, the same odor of isonitrile is produced, but the reaction is complicated and not perfectly understood. However, it is assumed that the benzene ring constituting the nucleus of the compound is partially broken down by the strong oxidizing action of the hypobromite or permanganate, and thus furnishes the necessary carbon substitution in the formation of isonitrile.

In making the carbylamine, isonitrile, or " isocyanide" test, as it may be called, it is preferable to have the solution strongly alkaline in every case to insure a more complete decomposition as well as quicker reaction and a more perceptible odor.

[CONTRIBUTIONS FROM THE CHEMICAL LABORATORY OF THE UNIVERSITY OF CALIFORNIA.]

\title{
ON THE PHYSICAL AND CHEMICAL PROPERTIES OF SOME CALIFORNIA OILS.
}

BY Walter C. Btaspale. Receiver Septemler :3, r895. $^{2}$

$T \mathrm{HE}$ investigations of which I would here record the results were undertaken some two years ago with three definite objects in view; first, the accurate determination of the limits of some of the standard constants of California olive oils; second, a practical test of the application of the Babcock method of determining adulterants in butter to a similar purpose for olive oil, and finally a determination of some of the constants of three new and hitherto undescribed oils of vegetable origin. In carrying out this work I have followed in general the methods laid down by Allen for the examination of oils, introducing such

1). Anal. Appl. Chem., 7, 354. 
modifications as more recent investigations have shown to be advisable.

The oils which have been used comprise the following samples:

I. Eleven samples of pure olive oil prepared under my own supervision from six standard varieties of olives, viz., Pendulina, Uvaria, Rubra, Redding Picholine, Nevadillo blanco, and Manzanillo, according to the usual method of preparing oil for the market in California. The essential difference between the samples marked "first" and those marked "second" is that the latter include oil from the pits as well as from the pulp of the olives. A small amount of warm water was added to the pomace before pressing in the latter case. These oils, as received from the press, were washed repeatedly and filtered until clear.

2. Two samples of mustard-seed oil of California manufacture.

3. One sample of oil from the kernel of the English walnut (Juglans regia) grown in the southern part of the state. This oil was prepared by extraction with petroleum ether.

4. One sample of oil prepared from the fruit of our live-oak (Quercus agrifolia) by extraction with petroleum ether. This yields a deep brown fluorescent oil, which readily solidifies at a temperature of $10^{\circ} \mathrm{C}$, and on long standing deposits waxy masses.

5. Oil prepared from the pine-nuts (probably the fruit of Pinus monophylla) found in our markets. This is a brown drying oil of a rather unpleasant odor and taste.

6. Oil prepared by Mr. V. K. Chesnut, from the fruit of the California nutmeg (Tumion Californicum).

7. Ten samples of the salad oils commonly sold in our groceries, comprising the following brands:

I. "Pure Olive Oil," J. Revalk, San Francisco.

2. "Pure California Olive Oil, Alpha Brand," Merriman Mfg. Co.

3. "California Olive Oil," Merriman Mfg. Co.

4. "Sierra Madra Olive Oil," Goldberg, Liebenbaum, and Bowen, San Francisco.

5. "Coburn's Pure Olive Oil," C. W. Coburn, San Francisco. 
6. "Extra Quality Oil, Huile Vierge," A Durand et Fils, Bordeaux.

7. "Fine Salad Oil," Franco American Oil Co.

8. "Cooper's California Olive Oil."

9. "Huile D'Olive Superfin," F. Aristoy, Bordeaux.

Io. " Huile Vierge," De Bossel Fil's, Marseilles.

The determinations and special tests to which these were sub. jected are as follows:

Specific Gravity.-This was in all cases determined by an accurately standardized pycnometer of about fifty cc. capacity.

Index of Refraction.-Determined by an Abbe refractometer of the Zeiss patern.

Thermal Degree.-By this I mean the increment of temperature resulting from mixing fifteen $\mathrm{cc}$. of oil with five cc. of concentrated sulphuric acid in a calorimeter with constant stirring, using an initial temperature of at least $20^{\circ} \mathrm{C}$. This method of carrying out the test was rendered necessary by the small quantities of many of the samples available; as the test is of no value except when compared with known oils this forms no serious objection to the results here presented. It is perhaps unnecessary to state that the same sample of acid was used in all the tests.

Viscosity Test.- I believe Prof. Rising was the first to suggest the possibility of using the factor representing the viscosity of the soap formed from a standard amount of oil in detecting adulterated olive oil. At his suggestion Mr. Babcock made the test with a number of samples of commercial oils, the results of which agreed entirely with those obtained by the application of standard tests to the same series of oils." The method which I have used, which is essentially the one adopted by Mr. Babcock, is as follows: Fifteen grams of oil are placed in a saponification flask with about thirty $\mathrm{cc}$. of water containing exactly seven and a half grams of potassium hydroxide and ten $\mathrm{cc}$. of alcohol and heated on a water bath until complete saponification has been effected. The resulting soap is washed into a large evaporating dish, heated until the alcohol is expelled, diluted to exactly $500 \mathrm{cc}$. at $15^{\circ} \mathrm{C}$, and the viscosity of the resulting solu-

1 Methods of Detecting Adulterations in Olive Oil. Report of Olive Grower's Convention, held in San Francisco, July, 18gt. 
tion determined by means of a torsion viscometer, the results being calculated in terms of the number of grams of sugar which it would be necessary to add to a liter of water in order to produce a solution of equal viscosity. In the case of the two mustard-seed oils, it was found necessary to dilute the solution to one liter in order to obtain a workable solution. My more recent experiences would induce me to make some few changes in this process, the most important of which would be a change in the working temperature from $15^{\circ}$ to $20^{\circ} \mathrm{C}$.

Saponification Number.-By this I mean the number of milligrams of caustic potash required to saponify one gram of oil. It has been determined by the standard method, operating upon two and one-half grams of oil.

Iodine Absorption.-For this determination I used the standard method of Hubl, basing the standard of the hyposulphite solution on pure potassium bichromate according to the method of the Association of Official Agricultural Chemists.

Melting Point of Fatty Acid.-For the determination of this constant I found it most satisfactory to prepare thin but wide glass tubes on the side of which a drop of the fatty acid is allowed to solidify. This is then attached to the bulb of a thermometer, placed in a water-bath and heated until a temperature is reached at which the fat begins to run down the side of the tube. Even when the greatest care is used considerable variations will be found in the results obtained from the same sample of oil.

Elaidin Test.-In this I have followed the method of Poutet, the one based on the use of a freshly prepared solution of mercurous nitrate. The time required for the production of a good elaidin varies considerably, and I have indicated this factor somewhat roughly in the accompanying table.

Milliau's Test.-The test proposed by that author and described in this Journal, 15, 153 .

An inspection of the accompanying table will show that most of the constants obtained for the pure olive-oils agree fairly well with those obtained for European oils. The iodine absorption, however, is exceptional since many of the results here reported are higher than the commonly accepted European standards. 


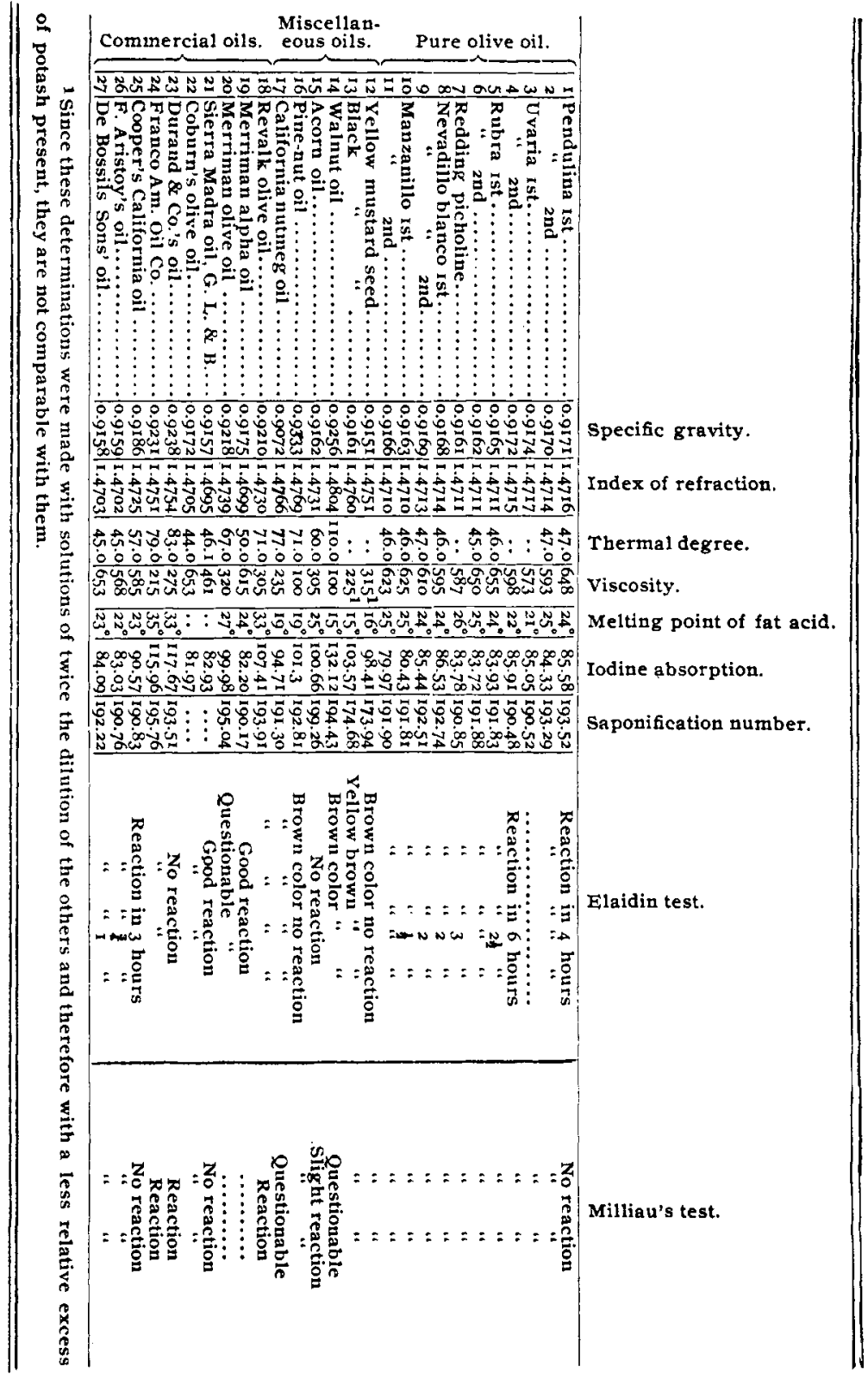


A possible explanation may be found in the fact that many of the varieties here represented are not those commonly used for the production of oil. Similar results have been obtained by Mr. G. E. Colby.' In the application of the elaidin test striking differences were observed both in the character of the elaidin and in the length of time necessary for its production. On the one extreme are oils of the Manzanillo type which produce a perfectly solid mass within an hour, whereas the two Uvaria oils produced only a partial solidification even after six hours. The facts seem to indicate that the test is not as reliable as has been supposed.

From a comparison of the results obtained from the oils of known purity with those obtained from the commercial oils it will at once be seen that Nos. I8, 23 and 24 are heavily adulterated with cottonseed-oil. No. 20 shows strong evidences of adulteration though the percentage is not as high as in the other cases.

I think it is also shown that the application of the viscosity test to the detection of adulterated olive oils is entirely successful; the variations in the figures obtained from the different samples of pure oil are considerable but not so great as to admit of confusion with any of the adulterated oils. In addition to the figures presented in the table, I have obtained the following results: For cottonseed-oil 280 , for sweet-almond oil 645 , for rapeseed oil 670 , for poppy-seed oil 95 , for sesame oil 415 , for lard oil 250 , and for peanut oil 220 , an array of figures which plainly shows the utility of this test. It will be seen that the only oils whose viscosity-constant approaches that of pure olive oil are almond, rape-seed and sesame. Of these the first is not likely to be used as an adulterant and the two latter are readily detected by other tests. The only oils showing a materially higher viscosity constant are the two mustard-seed oils, and it must be admitted that carefully proportioned mixtures of mustard and cottonseed-oils could not be detected by this test. The method promises to be of particular value in detecting lard oil for which we have had no satisfactory specific test.

Of the three hitherto undescribed oils No. 16 seem to agree in

1 Report of California Agricultural Experimental Station, 1890. 
most of its properties with other oils prepared from related plants, viz: Pinus sylvestris, Pinus picea, and Pinus abies in so far as these are known, and could probably be used for similar purposes.

No. 17 though obtained from a closely allied plant is an oil of quite a different character, but the data at present available is too insufficient to admit of a satisfactory prediction of its constituents. It might be of interest to note here that J. J. Rein, in a work entitled "The Industries of Japan," mentions the fact that an oil is prepared by the Japanese from the fruit of Tumion nucifera and used by them in their kitchens.

In conclusion I wish to express my thanks to Prof. Rising for suggestions received during the course of the work and also to the officials of the Experiment Station at Berkeley, through whose kindness I was enabled to obtain the samples of pure olive oil.

\section{THE DETERMINATION OF PHOSPHORIC ACID BY THE MOLYBDATE-MAGNESIA METHOD, AND BY VOLUMETRIC METHOD. ${ }^{1}$ \\ BY B. W. KILGORE. \\ Received September 30, 1895 .}

I $\mathrm{N}$ a summary statement of the results obtained last year by the members of the Association of Official Agricultural Chemists and other chemists cooperating with them by the official molybdate method on a solution of C. P. disodium hydrogen phosphate, I called attention ${ }^{2}$ to the fact that the results of nearly all of the analysts (twenty-eight) were high and some of them very materially so. The larger number of these analysts were experienced in this class of work. From this and other reasons I argued that the molybdate method, as usually worked, has a tendency to give high results, and that these high results are due to an excess of magnesium in the magnesium ammonium phosphate precipitate.

For the investigation of phosphoric acid methods for this association for 1895 , two chemically pure phosphate solutions and one mixed fertilizer were employed.

1 For description of this method, see methods of the Association of Official Agricultural Chemists for 1895 .

2 This Journal, 16, 793. 